\title{
A contribuição de Karl Marx para o desenvolvimento da ciência do direito*
}

\author{
Willis S. Guerra Filho**
}

Neste ensaio, pretendo sustentar que a contribuição de Marx para a epistemologia jurídica há de ser apropriada por quem intencione fazer um estudo científico do direito, o que significa o mesmo que se referir a quem tem por intenção fazer um estudo (científico) do direito com um sentido emancipatório, pois o ideal científico implica necessariamente na exposição e crítica do conhecimento dado, bem como na promoção do gênero humano a um estado mais liberto das circunstâncias adversas que o afligem.

Vou me ocupar da reconstrução de uma teoria da ciência do direito de corte estritamente marxiano, ou seja, levando em conta elementos fornecidos exclusivamente por Marx, em um período de seu pensamento, logo no início, antes dele dedicar a maior parte de seus esforços teóricos à economia política.

Para tanto, vou me valer dos resultados de pesquisa empreendida pelo filósofo do direito e brasilianist alemão, professor da Universidade de Frankfurt am Main, Dr. Wolf Paul. ${ }^{1}$ Essa pesquisa, apesar de feita já há vinte anos, ainda é pouco conhecida no Brasil. Agora, parece ter-se apresentado um momento mais propício para tomarmos contato com seus resultados, com a eclosão de movimentos como o do Direito Alternativo. A conclusão a que se chega vai então coincidir com teses difundidas por epígonos desse

* Palestra proferida no II Congresso Internacional de Direito Alternativo, Florianópolis, de 29.09 a 01.10 .93 .

** Professor da Faculdade de Direito da UFC.

1 Cf. Marxistische Rechtstheorie als Kritik des Rechts, Frankfurt am Main, 1974, esp. p. $90 \mathrm{ss}$.

R. Fac. Direito, Curitiba, a.28, n.28, 1994/95, p.69-74 
movimento, como Oscar Correas ${ }^{2}$ e Edmundo Lima de Arruda Jr., ${ }^{3}$ quanto à relevância, na atualidade, do aspecto epsitemológico-jurídico do pensamento marxiano.

A contribuição de Marx para a teoria epistemológica do direito se dá a partir da crítica a que submete o modelo de ciência proposto, pioneiramente, na chamada Escola Histórica do Direito, cujo representante máximo vinha a ser um ex-professor seu, na Faculdade de Direito da Universidade de Berlim, F. K. v. Savigny. É claro que, como já se pode antever, ao explorar essa perspectiva, logo nos depararemos com uma questão bastante tormentosa: a teoria da ciência do direito de Marx traria uma contribuição para a expansão do paradigma científico jurídico, o modelo dogmático de estudo do direito, ou na verdade, o que Marx vai propor não chega a configurar uma ciência jurídica alternativa, uma ruptura do paradigma dominante. Bem, antes de decidir sobre a compatibilidade entre a teoria do direito marxiana e aquela tradicional, examinemos o procedimento adotado por Marx ao tratar com a dogmática jurídica com o caso, por ele analisado, do roubo de lenhas.

Trata-se de assunto que viria a ser regulado por uma das leis produzidas pelo então "Ministro para Legislação" da Prússia, ninguém menos que Von Savigny, que se notabilizou por sua defesa do direito costumeiro, contra "a vocação de nosso tempo para a legislação". A idéia de Marx era, a partir da análise de um problema concreto - a colheita de pedaços de madeira, caídas, nas florestas a beira do Reno -, examinar o tratamento legislativo a ser dado ao assunto em projeto de lei, que passava a considerar como roubo de lenha esse fato, prevendo pena de multa ou trabalho forçados, prestados ao dono da floresta, por quem praticasse tal ato.

Em primeiro lugar, não se dá como aceita de antemão a compatibilidade de semelhante lei com a ordem jurídica, pelo simples fato de emanar de um poder autorizado para produzir tal norma. E se hoje isso nos parece trivial, à época não o era, tendo sido feito por Marx graças à postura crítica, negadora do que é dado, própria do método dialético, por ele adotado. Com

2 Cf. "Marxismo y derecho en America Latina", hoy, in Revista de Direito Alternativo, $\mathrm{n}$. 2, São Paulo, 1922, p. 146.

3 Cf. "Marxismo e Direito: alguns apontamentos", in Id., Introdução à Sociologia Juridica Alternativa, São Paulo, 1993, p. 90. 
o distanciamento da perspectiva formalista, dogmática - pela qual não importa que conteúdo esteja vertido na forma da lei, essa terá validade jurídica -, Marx vai se negar a ver como fatos idênticos e, sequer assemelhados, o roubo de lenha, através do corte de árvores, e a simples colheita de galhos caídos no chão, para fazer o fogo, absolutamente necessário à sobrevivência de um camponês, na Alemanha. Marx vê aí um atentado insuportável ao "princípio da adequação e verdade", ao qual deve se submeter também o direito, por mais que utilize ficções, analogias e outros artifícios para cumprir a função que lhe é própria. Marx vai com isso reportar-se a um topos argumentativo, que foi colocado no centro das discussões com o chamado renascimento do jusnaturalismo, no segundo pós-guerra, e depois, na década de 70, com a teoria crítica do Direito: aquele de natureza das coisas.

O Direito tem aí um limite à manipulação de conceitos, visando subsumir fatos concretos das hipóteses legais, abstratas: Não é da natureza jurídica das coisas equiparar roubo de lenha com colheita de galhos, e a lei não pode pretender alterar essa natureza das coisas, mas sim conformar-se à ela, sob pena de se tornar uma lei mentirosa, falsa, pois leva ao que Montesquieu chamou de corruption du droit par la loi. Chega-se, assim, a produzir-se um ilicito legal (gesetzliches Unrecht).

Um segundo ponto, assinalado por Marx, analisando o caso do ponto de vista estritamente jurídico, é o de que se transpõe uma medida sancionadora, a pena - e uma pena de trabalhos forçados, que se aplica sobre a pessoa do imputado, e não sobre o seu patrimônio -, do campo do direito público para aquele das relações jurídicas privadas. A própria multa, que se colocou como alternativa, vai para o particular, supostamente ofendido em seu direito de propriedade, e não para os cofres públicos. Verifica-se, assim, o que ele chama de uma jurisdição patrimonial, para defender não os interesses públicos, como deve ser, mas sim aqueles privados, de natureza patrimonial. Isso é a negação, pelo Estado, de si próprio; um suicídio, como diz Marx, pois rompe com princípios fundamentais do Estado de Direito, como a,isonomia e a generalidade das leis.

Um terceiro ponto, levantado por Marx, é o de que havia um costume estabelecido de recolher esses galhos livremente e, logo, um direito consuetudinário a fazê-lo, que foi simplesmente ignorado - e justamente por quem defendia uma concepção, como a da Escola Histórica, que toma o costume como fonte primária do direito, à qual a legislação e doutrina

R. Fac. Direito, Curitiba, a.28, n.28, 1994/95, p.69-74 
caberiam apenas explicitar. Aqui, Marx se depara com uma contradição flagrante entre teoria e prática, fundada nos interesses de classe do teórico - no caso, um aristocrata Von Savigny. Daí é que ele vai apontar para a necessidade imperiosa de se realizar uma crítica da ideologia, que mostra contradições entre a prática de alguém e sua própria concepção de mundo.

A próxima etapa do procedimento marxiano de análise crítica do direito vai ser então aquela em que desvenda, por trás do princípio legal das conseqüências jurídicas de um fato, um interesse querendo se impor a outro, um interesse patrimonial preponderando sobre interesses vitais do ser humano, do próprio gênero humano, cuja emancipação, segundo um topos argumentativo extraído da filosofia hegeliana - e já prenunciado por Kant -, é a própria tendência da "Weltbürgerlichen Gesellschaft", da sociedade civil universal.

Marx, nesse contexto, vai referir seguidamente a um outro topos, que ocupa lugar central na moderna teoria da argumentação, tal como é desenvolvida por Robert Alexy e outros, ${ }^{4}$ a partir do que propõe um dos mais recentes modelos de ciência jurídica: trata-se do topos da proporcionalidade. ${ }^{5}$ É desproporcional o sacrifício a que, no caso concreto examinado, se submete o interesse fundamental da classe desfavorecida em garantir sua subsistência, em nome do atendimento ao interesse particular do proprietário da floresta em manter o seu patrimônio.

Eis que, resumindo, o projeto de lei, que criminaliza a colheita de galhos nas florestas prussianas, fere princípios jurídicos fundamentais do Estado de Direito, tal como a igualdade perante as leis e a generalidade das mesmas, bem como princípios de racionalidade e de humanidade, donde se pode afirmar que, uma vez aprovada essa lei, ela estaria ferindo, assim, mais do que princípios de direitos, verdadeiros axiomas, em que se funda uma ordem jurídica.

Após lançar tantos elementos para renovação epistemológica do direito, os quais, se não romperam o paradigma em evolução desde a Roma

4 Cf., v.g., W. Krawietz et al., Argumentation un Hermeneutik in der Jurisprudenz, Berlim, 1979; Id./R. Alexy, Metatheorie juristischer Argumentation, Berlim, 1983.

5 Cf. Willis S.Guerra Filho, "O Principio Constitucional da Proporcionalidade", in Id., Ensaios de Teoria Constitucional, Fortaleza, 1989, p. 69 ss. 
Antiga, dessa ciência, muito o ampliaram, pois foram depois retomados pelas mais diversas linhas de pensamento na ciência jurídica, desde a jurisprudência dos interesses, prenunciada já no pensamento tardio de Jhering, até a atual jurisprudência das valorações; a tópica de Viehweg, ou o modelo tridimensional de Dreier/Alexy. Pois bem. após ter concebido, na prática de uma interpretação crítica, fazendo um estudo de caso, um procedimento capaz de desdogmatizar o sistema jurídico, tornando-o aberto, e não mais fechado, imune a críticas, algo absolutamente necessário ao pensamento científico; feito isso, Marx não prossegue seus estudos de direito, pois teria se deparado com uma tarefa prévia: a pesquisa daquele setor da vida humana em sociedade em que se dá o conflito daqueles interesses, de que as leis são a expressão, realizando-os ou obstaculizandoos. por ser um conflito gerado pela impossibilidade de se atender às necessidades das pessoas em geral na fruição de certos bens. Marx vai então se dedicar à pesquisa da base sob a qual se sustenta as representações ideais. como o direito, a base material, econômica. onde se produz e reproduz a vida em sociedade. A partir daí. no contexto de uma pesquisa que não era jurídica, mas que dizia respeito também ao jurídico, vão surgir colocações marxianas sobre o direito que servirão de fundamento a alegações de uma postura cientificista, mecanicista e positivista de sua parte. por tentar explicar os fenômenos jurídicos a partir do fenômeno econômico, tal como ele o descrevia. Essa crítica vem amparada, em grande parte, em desenvolvimentos posteriores da doutrina marxista, devidos a outros teóricos, especialmente aqueles que estavam comprometidos com um Estado que pretendia realizar a doutrina política marxista, os quais terminaram ideologizando completamente a teoria do direito marxista, tornando-a tão ou mais dogmática do que aquela dita burguesa. Crítica da ideologia é a nossa garantia epistemológica maior, como nos ensinou o próprio Marx.

A proposta que se faz, então, é que se desconstrua o pensamento jurídico de corte marxista, retrocedendo à própria obra de Marx, e, dentro dela, ao período inicial, em que se dedicou especificamente a estudos sobre o direito. E depois, que se reconstrua essa teoria, fazendo o que Marx não teria tido tempo de fazer pỏr ter necessitado dedicar o restante de sua vida concebendo uma teoria capaz de explicar e criticar o regime econômico capitalista, ou seja, que de posse dos resultados dessa pesquisa sobre a base economica, que se retome o estudo do direito, inserindo-o em contexto social e vital concreto, para detectar, inclusive, a influência transformadora dele sobre aquela base. Trata-se de uma proposta que pode indicar um novo

R. Fac. Direito, Curitiba, a.28, n.28, 1994/95, p.69-74 
caminho para a pesquisa do direito, a qual, sem deixar de ser "jurídica", apresentaria uma forte conotação científico-social. Em sendo assim, aponta para uma possibilidade inexplorada também para a teoria sociológica do direito. 